University for Business and Technology in Kosovo

UBT Knowledge Center

UBT International Conference

2015 UBT International Conference

Nov 7th, 9:00 AM - 5:00 PM

\title{
Traditional aspect and community socialization through public urban space- Study case Peja
}

\author{
Vlora Aliu \\ University for Business and Technology, vlora.aliu@ubt-uni.net \\ Binak Beqaj \\ University for Business and Technology, bbeqaj@ubt-uni.net
}

Follow this and additional works at: https://knowledgecenter.ubt-uni.net/conference

Part of the Architecture Commons

\section{Recommended Citation}

Aliu, Vlora and Beqaj, Binak, "Traditional aspect and community socialization through public urban spaceStudy case Peja" (2015). UBT International Conference. 65.

https://knowledgecenter.ubt-uni.net/conference/2015/all-events/65

This Event is brought to you for free and open access by the Publication and Journals at UBT Knowledge Center. It has been accepted for inclusion in UBT International Conference by an authorized administrator of UBT Knowledge Center. For more information, please contact knowledge.center@ubt-uni.net. 


\title{
Traditional aspect and community socialization through public urban space- Study case Peja
}

\author{
Vlora Aliu ${ }^{1}$, Binak Beqaj ${ }^{2}$ \\ UBT - Higher Education Institution \\ \{vlora.aliu'1, bbeqaj²\}@ubt-uni.net
}

\begin{abstract}
It's to be considered as an important issue, the issue of public space identification and social relation-ships of the community with them. It's the fact that social aspect of the people living in urban areas is considered as main aspect identified with:

- Inclusiveness and equity for different community categories

- Sustainable integration of urban development and

- $\quad$ Tradition

Considering this, the aim is to insist on development of those public spaces and definition of their role on social, societal and traditional aspect for the community.

Knowing that Peja as important urban area in Kosova, as city under modern development, is in the phase of developing new identity, so, actuality there is adoption in between transformation and integration. The aim of this paper is to present inter-relation between public spaces and social activities developed there, towards promotion of social, cultural and integral values for citizens.
\end{abstract}

Keywords: public space, social, urban, planning, societal, cultural, historic, traditional, integral

\section{Introduction}

In urban areas, there are different ty pes of public spaces ( $p$ arks, streets, squares, urban surrounding of buildings ...); that with the designation and content of its own (buildings, road inventory, green spaces, bridges, public art displays such as fountains, sculptures...) and through their level of usability have influential role in shaping the social identity, namely the development of social activities there.

Defining this, it should be started with daily experience of citizens in urban areas, in relation to mutual features and social interfaces of people with these mentioned public spaces.

The behavior of people in these areas varies depending on the area where citizens live, to which group they belong: group age, social, professional... therefore the frequented public spaces by the citizens may be internal or external , then depending on the knowledge, tradition, culture and the dimensions of citizens behavior, public spaces can be characterized as sy mbolic spaces as elements of social urban identity for citizens and all this depends on the extent of how much this urban social identity is incorporated in the behavior of individual and collective identity to the community. These are explained in the table Tab 1, as follows: 
Table. 1. Analy sis of social identity (source: Sergio Valera)

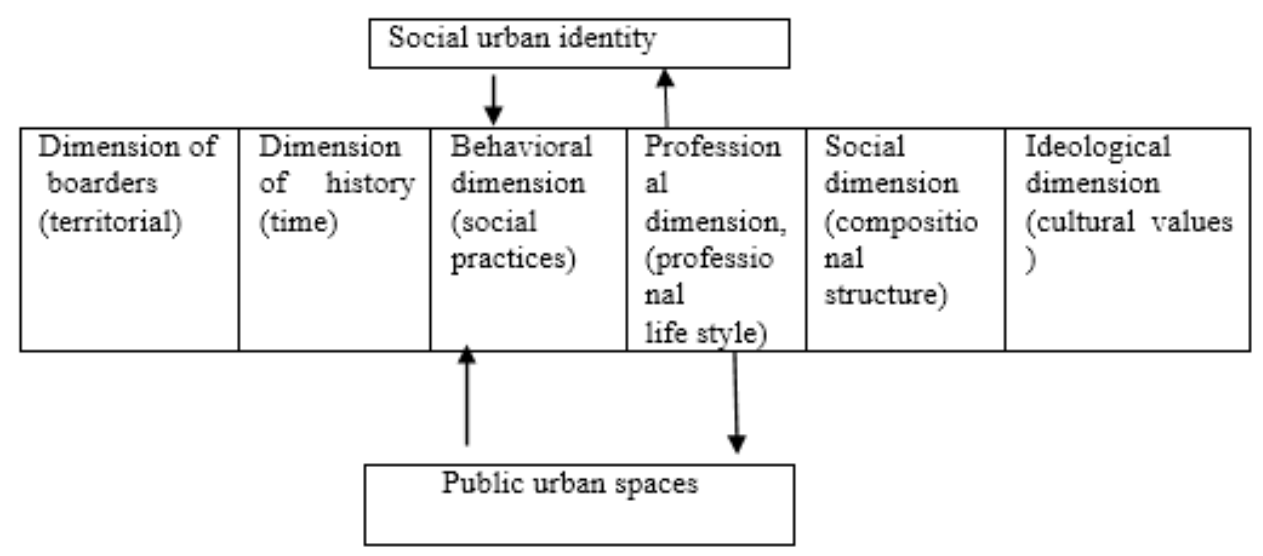

\section{Case study - Research}

Some of public spaces in the city of Peja, has been selected as a research subjects. The city of Peja is located in the western part of Kosova with specific features, historical heritage, cultural, industrial, trading, and touristic values.

The research methodology has multidimensional approach:

- Socio-historical development (documentary analysis)

- Quantitative (collection and processing of data)

- Qualitative (group discussion on the content of the information)

Research methodology is based on variables in identifying of public spaces:

1. The name of the public space

2. Their limits

3. Differences and functional similarities

4. The most representative city spaces

5. Interconnection of public spaces with the representative city spaces

6. The representative spaces for the future development

7. The most frequented spaces

Selected for This research are the main part of the city center of Peja, geographically located in the western part of Kosovo, with the following specific features: historic, heritage, cultural, trading, tourist, economic - social.

The areas that were explored are:

1. Center

2. Street " Mbretërasha Teuta " (ongoing)

3. City Square Haxhi Zeka

4. City Square "Skënderbe"

5. Small city park

6. "Promenade " 


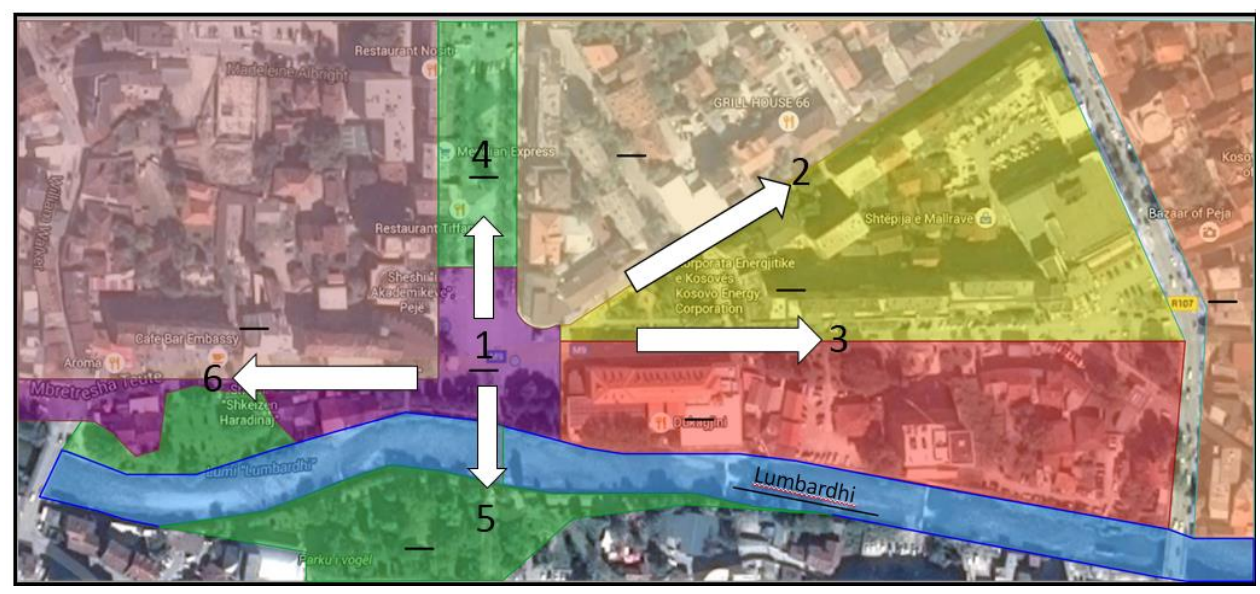

Fig.1. Focused city areas for research - composing the center of the city of Peja

The dominated functions identified from the research and analy sis of selected areas were taken as:

- $\quad$ Promenade

- Children play ground

- Square

- Connecting joint communication

- Gastronomy

\section{Case study, public space-Center}

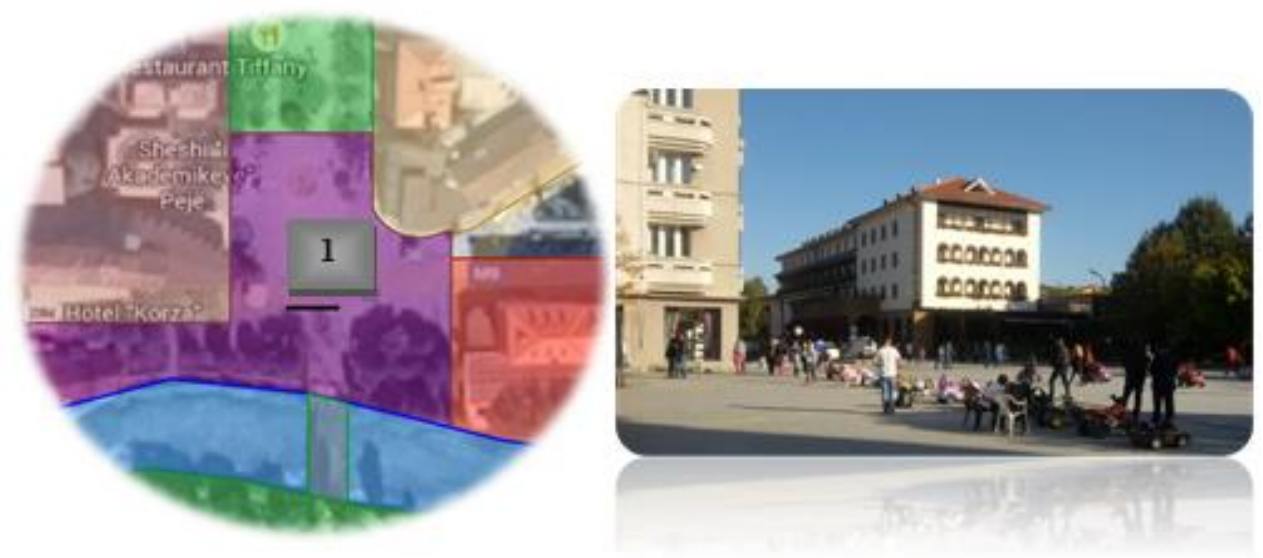

Fig.2 Analy sis of the center of Peja lay out (plans, photographs - authors)

Public space in the center of the city, as the main feature has it "square", which according to research stream that is frequented by middle-age structure and children's, as is presented in Table 2. 


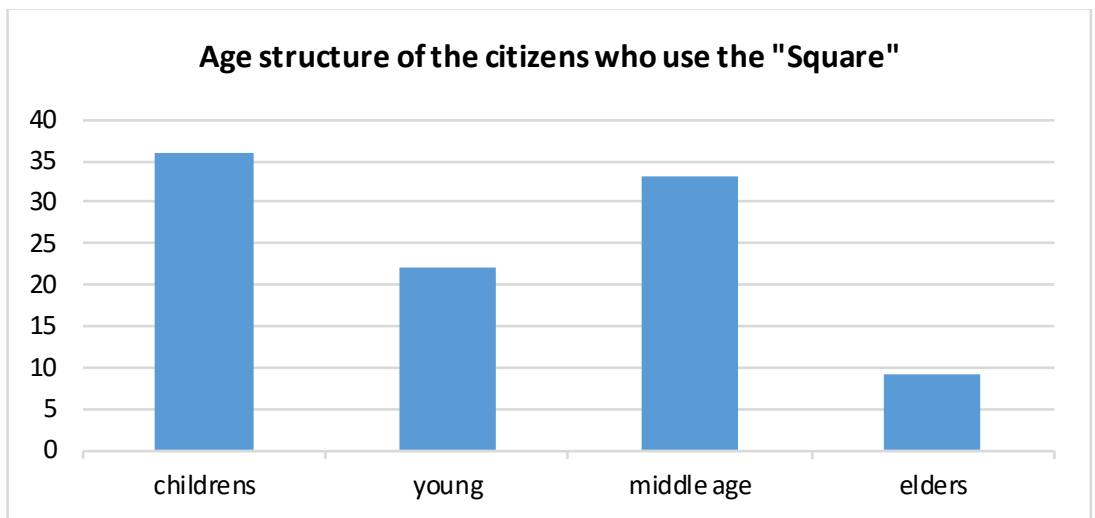

Table 2. Analy sis of the structure and age of the citizens (research September 2015)

The position of the "square" is the nexus main city attractive position, which borders with river Lumbardh and administrative buildings which also overlaps with other areas as city's minipark, with old trading center, hotel Dukagini and with city promenade. Besides this center is known with representative units like hotels, bridge, memorials...

\section{Case study, public space-street "Mbretëresha Teuta"}
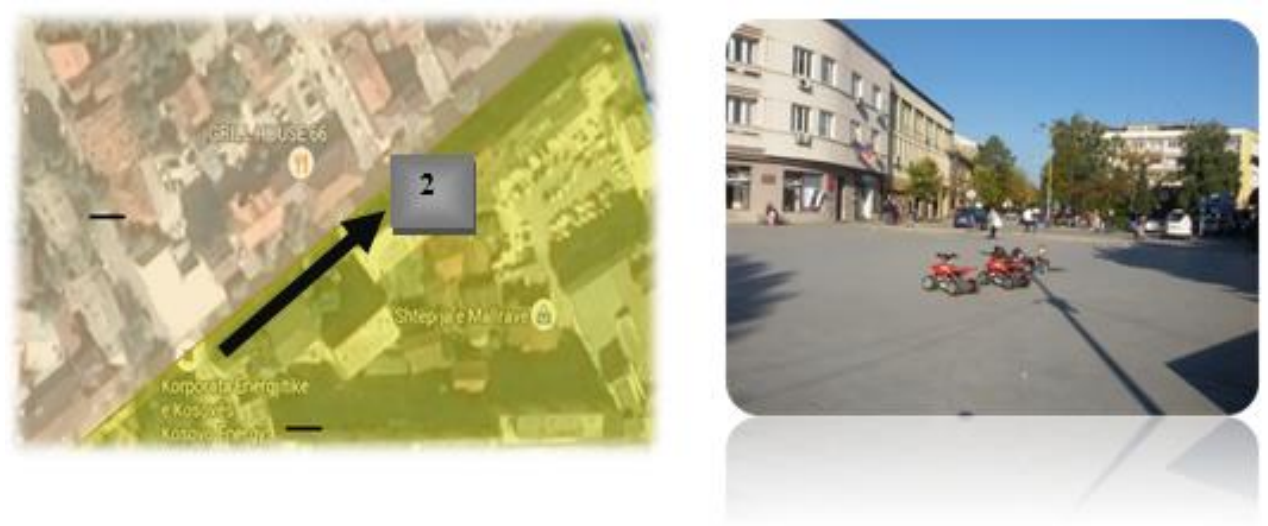

Fig.3 Analy sis of the road "Mbretëresha Teuta" (ongoing, lay out plans, photographs - authors) Street "Mbretëresha Teuta" is communication connecting node and is frequented mostly by young and middle age, as is presented in Tab.3 


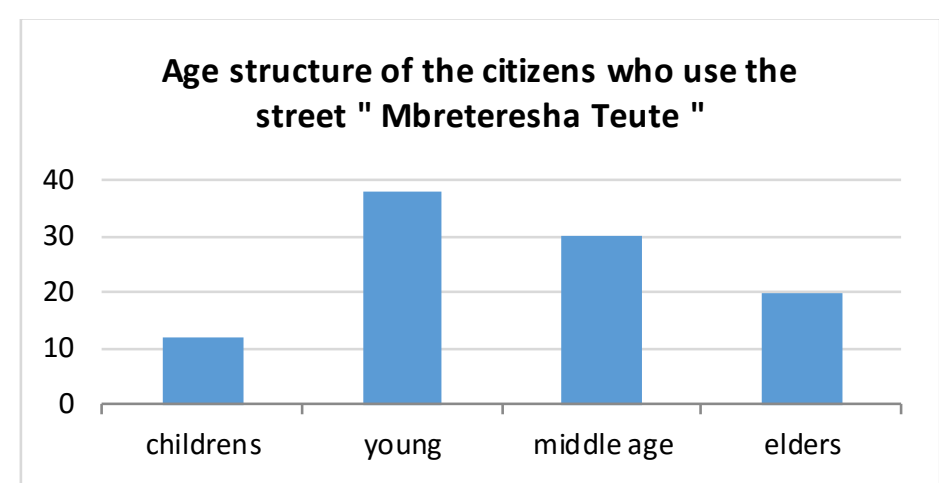

Table 3. Analy sis of the structure and citizens age Street "Mbretëresha Teute" (research September 2015)

Its position is the main road that borders the square with residential buildings and has conjunction with other spaces as municipality building, roundabout, trade commercial buildings etc. The most representative units along this street are: memorial from KLA war, municipality building and, collective housing/commercial buildings.

\section{Case study, public space-street "Haxhi Zeka"}

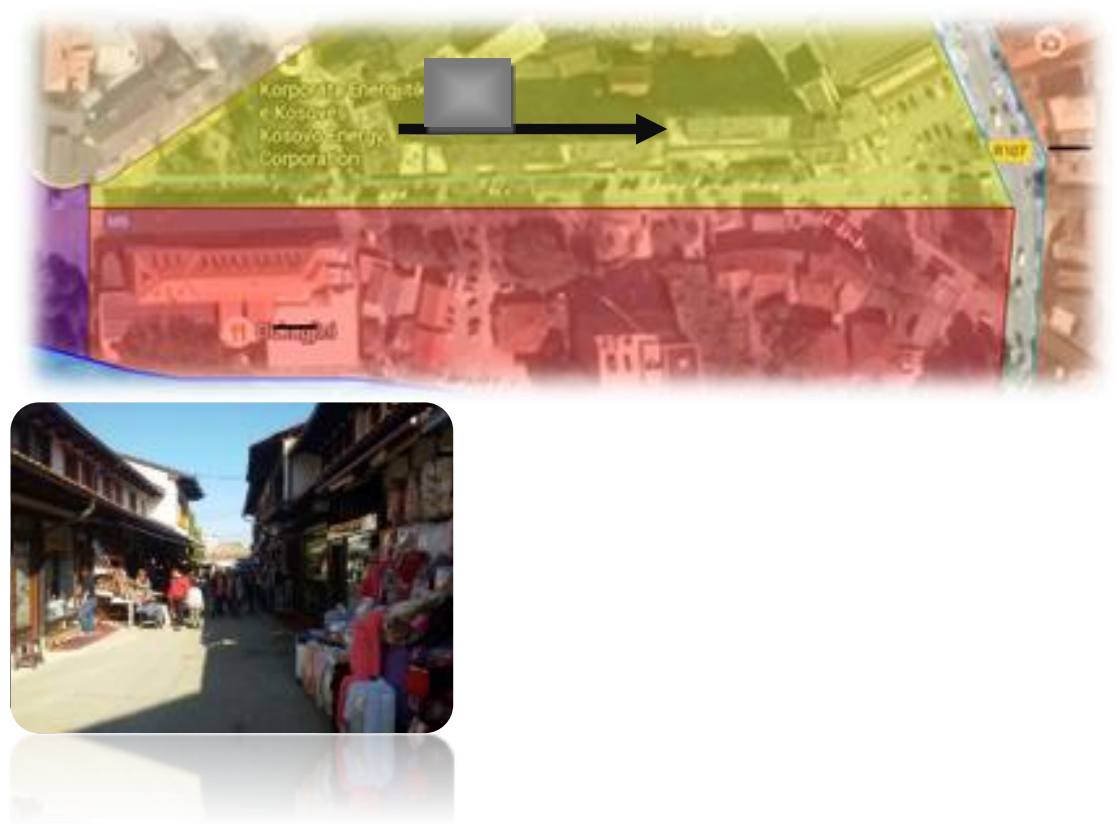

Fig.4 Analysis of the square "Haxhi Zeka" (lay out plans, photographs - authors)

Square "Haxhi Zeka" is surrounded by different buildings of collective housing and commercial units that is the main connecting street that leads to the old trade center "Qarshia e vjetër". This square is mostly frequented by middle age and old age of citizens, as is presented in Tab.4 


\section{Age structure of the citizens who use the square "Haxhi Zeka"}

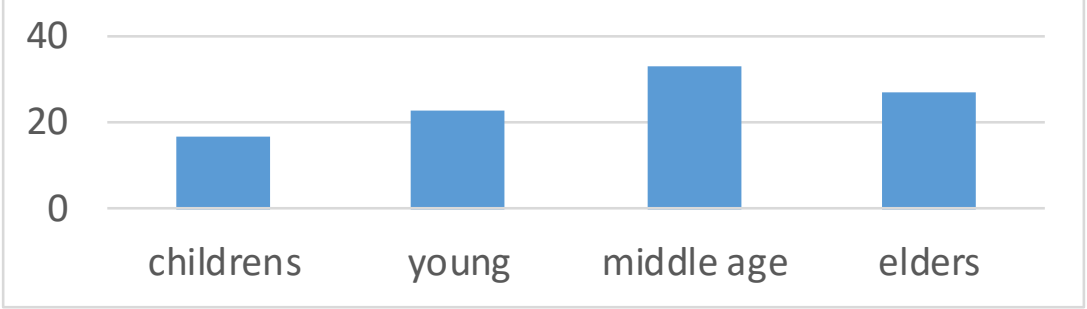

Table 4. Analy sis of the structure and citizens age Street - Square"Haxhi Zeka“(research September 2015)

There prime position due to proximity with Lumbardh river, and bordering with Trade center, old trade site Interconnection, museum and with other spaces such as residential, business, catering, etc. makes this square most frequented point. The dominated buildings are those of collective housing, where buildings have an identical height and a good distance to each other.

Representative units are: Lumbardhi River and Dukagjin hotel who give the site a more attractive appearance.

\section{Case study, public space- "Parku i vogel"}
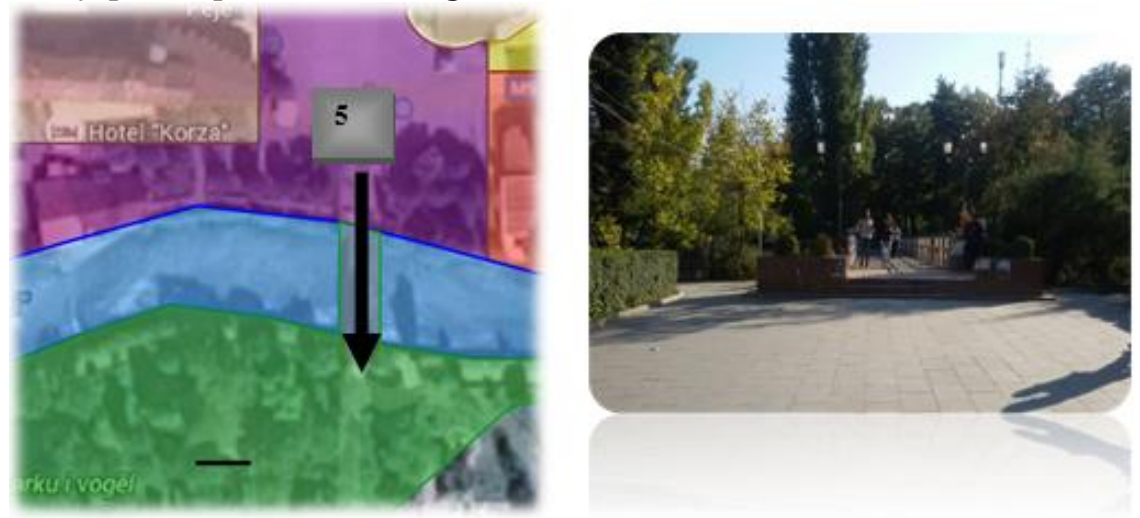

Fig.6 Analy sis of the small city park (layout plans, photographs - authors) 


\section{Age structure of the citizens who use the small square park}

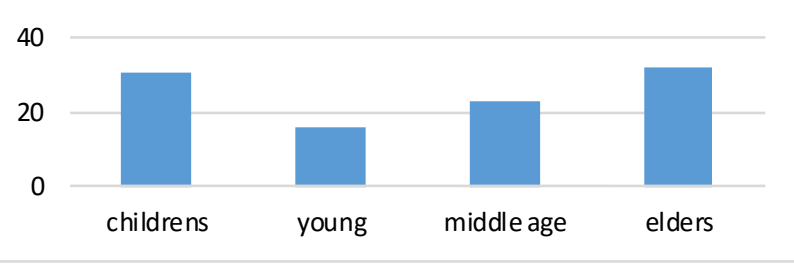

Table 6. Analy sis of the structure and citizens age - a small city park (research September 2015)

The Small city park with main function greenery and space for recreation that mostly used by old age of citizens and children's. Small City Park with its position, is dominant area in the city center because it is situated alongside Lumbardh River and connected with other public spaces and city neighborhoods. The Bridge which connects square with the park is characteristical point to this park but in terms of security its flowed low maintenance decreases the feeling of security of citizens there. The park is linked with Hotel Dukagiin with square "Scanderbeg" the square "Haxhi Zeka", from the river Lumbardhi and it's characterized with different varieties of greenery and pedestrian paths.

\section{Case study, public space-"Promenade"}
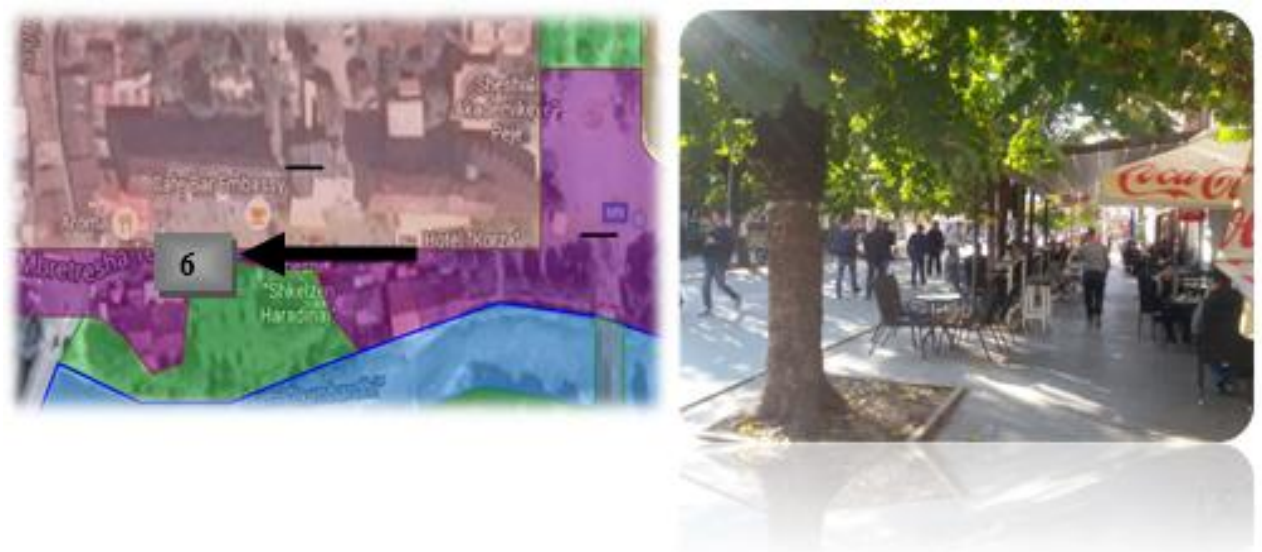

Fig.7 Analy sis of the road " Mbretëresha Teuta" (lay out plans, photographs - authors)

The public space "Promenade", is dominated by gastronomy which is frequented mostly by young and middle age, as is presented in Tab. 7

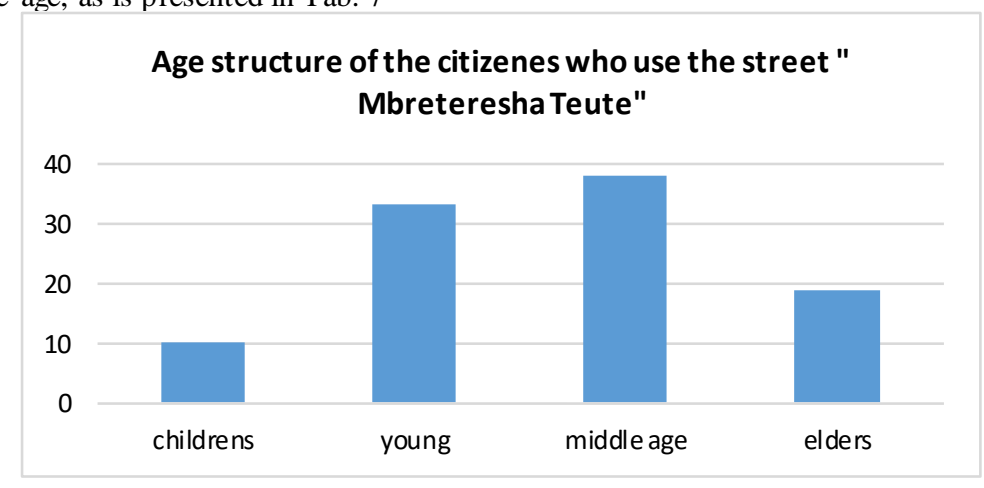


Table 7. Analy sis of the structure and age citizens - "Promenade" “(research September 2015)

Gastronomy in this area, itself includes different units where teenagers and medium age of citizens can have fun and spend their leisure time. This promenade is acting as a bridge connecting other public spaces in city center. Bordered by collective residential buildings -and individual, also with Square "Scanderbeg" the Catholic Church, and with the "Sand bridge" which connects the roads frequented by vehicles

The most representative units walkability area, the greenery that affects to the urban landscape as well as cafeterias and restaurants which show a zest in this part of the city during most of the day.

\section{Conclusions and Recommendations}

Finally on terms of development of tradition and socialization of people in six public spaces selected for research and analysis, in the city of Peja, can be concluded that it is more than necessary:

1. The use and arrangement of the promenade along river Lumbardhi, in order that citizens exploit it through walking, meetings will affect the public health of the citizens. Can be developed as emblem of the city which will guide the citizens visiting other central points, also providing detailed information's for visitors. Adding some more greenery will also affect the urban/architectural landscape of area.

2. Facades of the buildings, would positively impact on the adjustment of urban landscape and will affect people's feeling of satisfaction and utilizing the use of this spaces more sensitively which also affects their feeling on urban identity .

3. Adjusting the path for cyclists is very important because the road where activities are held would get shorter and efficient. Public garages in the area will be of an important help since in the square there are a lot of activities going on.

4. There is a lack of parking lots for the residents of the area also for the visitors. Public transport in this part will help a lot connecting the public spaces and avoiding chaos in traffic, helping the citizens in performing their daily activities such as, work travel, trading, shopping through walking-green traffic.

5. Extending the boulevard to the square will create a space to be multiply used and as an interconnection with traditional and cultural aspects of the surrounding urban areas. By removing the illegal sellers it would create a better view and easier area functionality for residents. Also the removal of parking lots on this road would affect in the expansion of the square that will make it safer and more frequented area.

6. Through the establishment of "temporary market" in daily basis or certain day s, it would be a good opportunity to promote local values, local products and traditions.

7. Maintenance and adding urban inventory will help more increasing the use of the areas and improving their view. Continuity of the bicycle path will help this part to decrease the air pollution and noise which is done by different vehicles.

8. Adjust the bridge which connects the square with small park will assist in the security of citizens and accessibility would be grateful. It will also affect the purity of Lumbardh and the urban landscape in this area. The small park has sufficient greenery which is maintained from time to time but it lacks the play ground for children.

9. Promenade along Lumbardh would be required especially for the old age as they need a fresh climate and a sufficient space for a daily walk. The park lighting and increase of urban inventory will greatly affect that citizens spend their free time in this park as well as its accessibility would be great even in the organization of various events such as tournaments and exhibitions. Public toilets in this part are more than necessary since the awareness of citizens would be great if these exist but also maintained.

10. Since the area of gastronomy is used mainly by young people it will increase its attractiveness of information, encouraging debate and modernization of space as additional element of identity. Planning and redesign of terraces is necessary in order for citizens to have more space for developing their activities. As it lacks the lightning by improving it would create a greater security for the area. Digitization of facades would affect the 
socialization of citizens which would enable the communication and interpretation of various activities such as sports, cultural, political.

Eventually these proposals for alterations in the center of Peja would create a new identity based on tradition and modernity, through synthesis of the way of the development of civic life in an urban multifunctional environment.

\section{References}

1. Charles Montgomery, "Transforming our lives through urban design”, (2013)

2. Setha M. Low, Neil Smith, "The politics of public space", (2006)

3. Peter John, "Analyzing public policy", (2013)

4. Binak Beqaj, "Zhvillimi urban, planifikimi dhe dizajni”, (2015)

5. Jan Gehl, "Life between buildings using public space", (2011)

6. Jan Gehl, "Cities for people", (2010)

7. Ministry for the Environment, Wellington, "The Value of Urban Design. The Economic, Environmental and Social Benefits of Urban Design". (2005)

8. Baltic University Urban Forum, "Built Environment and Revitalization", (2006)

9. John Chang, "The problematization of urban spravl in the United States", (2006)

10. EU Commission, "Making our Cities Attractive and Sustainable", (2010)

11. World Bank, "Measuring Growth and Change in Metropolitan Form", (2012)

12. World Bank, "Vleresimi i sektorit urban ne Shqiperi", (2007)

13. Sergi Valera, "Public space and Social Identity". 